\title{
Birch pollen influence the severity of atopic eczema - prospective clinical cohort pilot study and ex vivo penetration study
}

This article was published in the following Dove Press journal:

Clinical, Cosmetic and Investigational Dermatology

29 October 2015

Number of times this article has been viewed

\author{
Regina Fölster-Holst' \\ Jagoda Galecka' \\ Sigo Weißmantel' \\ Ute Dickschat ${ }^{2}$ \\ Frank Rippke ${ }^{3}$ \\ Kerstin Bohnsack ${ }^{3}$ \\ Thomas Werfel ${ }^{4}$ \\ Katja Wichmann ${ }^{4}$ \\ Matthias Buchner' \\ Thomas Schwarz' \\ Annika Vogt ${ }^{5}$ \\ Jürgen Lademann ${ }^{5}$ \\ Martina C Meinke ${ }^{5}$ \\ 'Department of Dermatology, \\ Venerology and Allergy, University \\ of Kiel, ${ }^{2}$ Wörth, ${ }^{3}$ Beiersdorf \\ AG, Hamburg, ${ }^{4}$ Department of \\ Dermatology, Venerology and Allergy, \\ Division of Immunodermatology and \\ Allergy Research, Hannover Medical \\ School, Hannover, ${ }^{5}$ Department \\ of Dermatology, Venerology \\ and Allergology, Charité - \\ Universitätsmedizin Berlin, Berlin, \\ Germany
}

Correspondence: Martina C Meinke Klinik für Dermatologie, Venerologie und Allergologie, Charité -

Universitätsmedizin Berlin,

Charitéplatz I, I0117 Berlin, Germany

Tel +4930450518244

Fax +4930450518918

Email martina.meinke@charite.de

\begin{abstract}
There is little clinical evidence for a correlation between the severity of atopic eczema (AE) and pollen exposition. To obtain more data, we performed a clinical cohort pilot study about the influence of pollen on AE between sensitized and nonsensitized subjects and an experimental study addressing the cutaneous penetration of pollen into the skin. Fifty-five patients were monitored during birch pollen season. To study the cutaneous penetration, grass pollen allergens were applied on excised skin and the uptake in CD1c-expressing dendritic cells was investigated. The correlation between environmental pollen load and severity of the Scoring Atopic Dermatitis (SCORAD) score and pruritus was observed, regardless of the status of sensitization. The sensitized group recovered significantly worse after the birch pollen season. Remarkably higher amounts of pollen allergens taken up by CD1c cells were detected in epidermal cells derived from skin explants with a disturbed epidermal barrier. These findings suggest an exacerbating role of pollen in $\mathrm{AE}$ utilizing the epidermal route.
\end{abstract}

Keywords: aeroallergens, atopic eczema, seasonality, skin antigen-presenting cells, skin barrier penetration

\section{Introduction}

Atopic eczema (AE) is the most frequently occurring chronic inflammatory cutaneous disease in children. ${ }^{1}$ It is characterized by typical eczema in the crook of the elbows, ankles, and knees, and is accompanied by persistent pruritus. The pathogenesis is extremely heterogeneous and driven by a complex interaction of genetic and environmental factors. ${ }^{2}$ The two main dysfunctions responsible for the symptoms are a deficiency in the epidermal barrier and a dysregulation of the immune system. Both disturbances are genetically controlled. ${ }^{3}$

The group of atopic diseases comprises (besides AE) allergic rhinitis, conjunctivitis, asthma, and food allergy, all of which are characterized by an enhanced predisposition to develop sensitizations and allergies against natural antigens, derived from house dust mites, pollen, pets, or foods. ${ }^{4}$ While the causal link between sensitizations against inhalant allergens for allergic rhinitis and asthma is clear, the exposure to these natural environmental antigens is considered less important when referring to the induction of relapses of the $\mathrm{AE}$.

There are some arguments indicating that environmental antigens may indeed be important for the pathogenesis of $\mathrm{AE}^{3}$ These include the sensitization against inhalant allergens, the improvement of the skin by reducing the exposure to allergens and, vice versa, the deterioration of the skin when exposed to high amounts of allergens. ${ }^{5}$ 
To further elucidate the role of epicutaneous exposure to pollen in influencing AE, we monitored the clinical course of AE before, during, and after a birch pollen season. In addition, experimental investigations were performed addressing the cutaneous penetration of pollen allergens (PA) in skin samples. The hypothesis is that the AE is more pronounced during pollen season, which could be explained by penetration of PA into the disturbed skin.

\section{Materials and methods}

\section{Patients}

The study was performed in 2009 at two dermatological centers in Northern Germany (in Kiel and Hannover). For this pilot study, we aimed to enroll as many adult atopic patients from the dermatologic outpatient clinic that fulfilled the Criteria of Hanifin and Rajka. ${ }^{6}$ The subjects were consecutively recruited from March 2009 until 3 days before the start of the birch pollen season, as determined by the institute of the national ministry of traffic and digital infrastructure (http://www.dwd.de/pollenflug). Subjects screened after this day were excluded to ensure that local differences in birch pollen flight would not interfere with baseline data. The eligible subjects were divided by their status of specific immunoglobulin (Ig)E against birch pollen (Thermo Fisher Scientific, Waltham, MA, USA). A radioallergosorbent test (RAST) was performed for each subject on visit 1. All subjects with carrier-polymer-system (CAP)-Class 2 or above were included into the sensitized group, and those with classes below CAP-Class 2 fell into the nonsensitized cohort, respectively. The patients were examined during six visits: in the preseason (visit 1); at the beginning of the season (visit 2); 1 week (visit 3) after the season began; 2 weeks (visit 4) after the season begin; at season end (visit 5); and 2 weeks after season end (visit 6). On each visit, the patients were clinically examined and the severity was scored using the Scoring Atopic Dermatitis (SCORAD) scale. In addition, pruritus and sleeplessness were recorded by a visual analog scale. At the first visit, the patients completed a general questionnaire (detailed in section Questionnaires), and a specific study questionnaire at visits 2-6.

Possible confounders include sensitization to other allergens during the same period (we controlled for those using a pollen trap and noticed only minor concentrations of cupressae or carpinus, less than one-tenth of the birch pollen concentration), as well as individual trigger factors like stress or time of exposure to the outside environment. These were projected to play a minor role, since individual triggers may be controlled over the number of subjects; the exposure by simply opening the window once a day was considered to bear enough pollen to trigger symptoms.

The subjects were allowed to use a stable topical therapy of mild-to-moderate glucocorticoids throughout the study. Also, antihistamines were free to use for the subjects, since no significant impact on the eczema was expected. ${ }^{7}$ Any data from subjects who participated in less than five of six visits were excluded.

Patients were asked to evaluate their condition according to a skin score $(0-3 ; 0=$ none, $1=$ mild, $2=$ moderate, and $3=$ severe) and to document the data in a diary. The data were made anonymous by means of codification. The study had been approved by the Ethics Committees of the University Hospital Schleswig-Holstein, Campus Kiel (Kiel, Germany), and of Hannover Medical School (Hannover, Germany). Written informed consent had been obtained from each participant.

\section{Questionnaires}

\section{General questionnaire}

The general questionnaire included data on the time of onset of AE, patient and family history of atopic diseases, sensitization especially to birch pollen, and cross reactions to food. Furthermore, patients were questioned regarding specific immunotherapies, medications for treating their AE, general diseases, and respective medications.

\section{Study questionnaire}

In the study questionnaire, which was completed during the visits 2-6, the patients stated the following: 1) how their skin had changed since the last visit (clearly improved, slightly improved, unchanged, slightly deteriorated, or clearly deteriorated); 2) which skin areas were affected by the change (air-exposed areas like the face, back of the hands/forearms, and unexposed skin areas); and 3) which topical and systemic drugs had been administered (cortisone cream/ointment, cortisone tablets, antihistamines, or calcineurin inhibitors cream/ointment).

\section{Dermatological Life Quality questionnaire}

The Dermatological Life Quality Index (DLQI) should reflect the patient's quality of life. ${ }^{8}$ It includes ten questions, the answers to which were added to a final score (scale of 0-30 scores): 0-1, not impaired; 2-5, slightly impaired; 6-10, moderately impaired; 11-20, strongly impaired; and 21-30, extremely impaired.

\section{SCORAD}

The severity of the AE was determined by the SCORAD index established by the European Task Force on Atopic 
Dermatitis. ${ }^{9}$ This index is composed of both objective parameters (extent and intensity) and subjective parameters (pruritus and sleeplessness), and serves as a clinical instrument for severity assessment. The extent of the AE is assessed according to the rule of nines with consideration of the patient's age. Also, the extent was analyzed separately for exposed (face, forearms, hands) and unexposed skin (breast, back). The intensity includes the morphological criteria, such as the erythema, edema/papule formation, weeping, crust formation, excoriation, lichenification, and dryness of the nonaffected skin. The SCORAD is calculated using a formula reflecting the individual parameters with their specific weight. The SCORAD was recorded for every patient on each of the six visits.

\section{Sleeplessness, pruritus}

Pruritus and sleeplessness were recorded daily by the patients using a visual analog scale (scale: 0-10; ranging from no pruritus to unbearable pruritus and sleeplessness, respectively) during all weeks of the study.

\section{Changes in $\mathrm{AE}$ (subjective assessment)}

The AE, as subjectively assessed by the patients using the given categories, "clearly improved $(-2)$ ", "slightly improved $(-1)$ ", "unchanged $(0)$ ", "slightly deteriorated $(+1)$ ", and "clearly deteriorated $(+2)$ ".

\section{Pollen measurements (Burkhard trap)}

The daily amounts of birch pollen in the air were determined with the aid of the Burkhard pollen trap. During this procedure, air is collected $(10 \mathrm{~L} /$ minute $)$ and airborne particles are deposited on a petrolatum tape mounted on a drum. Analysis was performed with light microscopy. ${ }^{10}$

\section{Labeling of the PA}

Grass PA were labeled with a fluorescent dye, as described in detail by Jacobi et al. ${ }^{11}$ The used extract contained purified allergens with protein sizes from 10 to $100 \mathrm{kDa}$. Two ampoules with $1.26 \mathrm{mg}$ extract of grass pollen (Gräsermischung, 450,000 standardized quality units; ALK-Scherax, Hamburg, Germany) were dissolved in $1 \mathrm{~mL}$ of phosphate buffered saline (PBS) buffer (Sigma-Aldrich Co, Chemie $\mathrm{GmbH}$, Steinheim, Germany). A $10 \mathrm{mM}$ solution (2 mg in $1 \mathrm{~mL}$ of PBS buffer) of fluorescein isothiocyanate (FITC) (Sigma-Aldrich Co) was added to the pollen extract. This mixture was incubated in the dark for 2 hours at $4^{\circ} \mathrm{C}$. The FITC-labeled pollen proteins were purified using membrane dialysis (Spectra/Por ${ }^{\circledR}$, MWCO 6-8000; Theodor Karow
GmbH, Berlin, Germany). An excess of L-alanyl-L-glutamine (Dipeptamin $^{\circledR}$; Fresenius Kabi Deutschland $\mathrm{GmbH}$, Bad Homburg, Germany) was added to the FITC-labeled proteins and the dialysate, to inactivate nonbonded FITC. Both solutions were incubated for 2 hours at $4^{\circ} \mathrm{C}$.

Aliquots were dried at $30^{\circ} \mathrm{C}$ using a lyophilisator (Concentrator 5301; Eppendorf, Hamburg, Germany). The dry lyophilisates were stored at $-20^{\circ} \mathrm{C}$ in the absence of light. The lyophilisates of the dialysate were used as controls in the experiments. For application onto human skin, one aliquot of the lyophilisates $(450,000$ standardized quality units) was dissolved in $240 \mu \mathrm{L}$ of PBS $(1,875$ standardized quality unit/ $\mu \mathrm{L})$.

\section{Skin explants}

Freshly excised skin samples were obtained from healthy nonatopic volunteers undergoing plastic surgery. The skin was investigated visually by a physician before surgery and possible skin diseases were excluded through inquiry. Written informed consent was obtained. Tissue sampling was approved by the Institutional Ethics Committee of the Medical Faculty of the Charité - Universitätsmedizin Berlin (Berlin, Germany) and followed the ethical rules stated in the Declaration of Helsinki.

\section{Application of PA}

Normal skin was carefully separated from the subcutis and fixed onto a board. The excised skin surface was carefully investigated for scratches or injuries. On each skin sample, an application area of $16 \mathrm{~cm}^{2}$ was delineated by a skin surface marker, leaving safety margins of $0.5 \mathrm{~cm}$ to the border of the tissue to avoid penetration of PA sideways into the tissue. Prior to the application of the PA, in six cases, cyanoacrylate skin surface stripping (CSSS) was performed twice, as described, ${ }^{12}$ using superglue (UHU GmbH and Co KG, Bühl, Germany). Briefly, in CSSS, a drop of cyanoacrylate is applied on the skin surface and adhesive tape is placed on top of it. When the tape is removed, the hairs and approximately $30 \%$ of the stratum corneum and follicular casts are obtained. PA in PBS $\left(10 \mu \mathrm{L} / \mathrm{cm}^{2}\right)$ was applied and the tissue samples were incubated for $15-16$ hours at $37^{\circ} \mathrm{C}$ in a humidified chamber. Skin samples from 12 different donors were prepared.

\section{MACS separation of epidermal cells}

Epidermal cell suspensions were generated, as described previously, ${ }^{13}$ with slight modifications. Briefly, dispase digestion (2.4 U/mL of Dispase I; Hoffman-La Roche Ltd, Basel, Switzerland) was performed for 3 hours at $37^{\circ} \mathrm{C}$ to 
separate epidermis from dermis. The epidermal sheets were treated with trypsin $(0.025 \%), 1.5 \mathrm{mM}$ of $\mathrm{CaCl}_{2}$ in $\mathrm{PBS}$, $\mathrm{pH} 7.4$, for 10 minutes at $37^{\circ} \mathrm{C}$ to isolate the epidermal cells. After resuspension of the cells, Magnetic Activated Cell Sorting (MACS) separation with anti-BDCA-1 (anti-CD1c) antibodies was performed twice according to the manufacturer's recommendation (CD1c blood dendritic cell antigen [BDCA-1] Dendritic Cell Isolation Kit; Miltenyi Biotec, Bergisch Gladbach, Germany). This procedure ensures that mainly Langerhans cells were selected.

\section{Laser scanning microscopy}

MACS-separated epidermal cells were investigated after transcutaneous application of PA using a confocal laser scanning microscope (LSM 4000; Carl Zeiss Meditec AG, Jena, Germany). The excitation wavelength of an argon laser at $488 \mathrm{~nm}$ was used for the detection of the dye-labeled PA. The fluorescent signal was detected cell by cell in the spectral range between 590 and $650 \mathrm{~nm}$. The mean intensity in the images was determined using ImageJ. The signal of the background was subtracted from the signal in the cells. The intensity for no fluorescence was evaluated in the range between 0 and 5 arbitrary units (AU), a weak fluorescence between 6 and 24, and strong fluorescence between 25 and 60. Three fields of view were analyzed.

\section{Statistical analysis}

The clinical results were statistically analyzed descriptively by type of data, stating the absolute and relative frequency for categorical data, as well as the mean value and standard deviation in the case of continuous data. The program SAS version 8.2 for Windows (SAS Institute Inc., Cary, NC, USA) was used. Diagrams were prepared using Microsoft Office Excel 2003.

For statistical analysis of the experimental results, SPSS 19.00 for Windows (IBM Corporation, Armonk, NY, USA) software was used. Data from the experimental section were analyzed using nonparametric tests. Firstly, the relatedsamples Friedman's two-way analysis of variances by ranks was performed. Differences among the means of groups were analyzed by the Wilcoxon test, considering significance at $P<0.05$.

\section{Results}

\section{Clinical study}

Fifty-five adult patients suffering from AE (37 females and 18 males; median age, 38 years) were recruited (49 from Kiel, Germany; 6 from Hannover, Germany). Thirty-three of the patients were sensitized to birch pollen; 22 were not sensitized to birch pollen. Two subjects (not listed) were excluded because their data were not completed for all visits.

Table 1 shows the demographic data of the patients with AE, including the history of further atopic diseases. The data acquired in the three most important visits were selected to show the results of the study. In the following, they were described as preseason, peak, and postseason.

The changes in the SCORAD were documented for patients with sensitization and for those without sensitization to birch pollen comparing preseason, peak, and postseason of birch pollen. During the birch pollen season, the increasing concentration of airborne pollen was accompanied in a delayed fashion by a significant deterioration in the SCORAD of the total population (between preseason and peak, $P=0.012$ ). Once the pollen concentration had decreased, the SCORAD improved again significantly (between peak and postseason, $P<0.0001)$ and had almost reached the original level, on average, when the patients were followed up after the pollen season. Even though no significant difference was found for the increase of SCORAD between birch pollensensitized and nonsensitized patients $(P=0.934)$, the decrease for pollen-sensitized patients was significant $(P=0.028)$. Respective differences for pruritus and sleeplessness were not significant (Table 2).

The subjective assessment of the AE showed a similar behavior as the pollen count (Figure 1), except for the two rainy days at the beginning of the season. Such days influence the pollen concentration, but not the much slower changing clinical symptoms of AE. Some days after the pollen peak, deterioration of AE was observed,

Table I Demographic data

\begin{tabular}{|c|c|c|c|}
\hline $\begin{array}{l}\text { Subject } \\
\text { parameter }\end{array}$ & $\begin{array}{l}\text { Patients } \\
\text { sensitized to } \\
\text { birch pollen }\end{array}$ & $\begin{array}{l}\text { Patients } \\
\text { nonsensitized } \\
\text { to birch pollen }\end{array}$ & Total \\
\hline \multicolumn{4}{|l|}{ Patients } \\
\hline $\mathrm{N}(\%)$ & $33(60.0)$ & $22(40.0)$ & $55(100)$ \\
\hline \multicolumn{4}{|l|}{ Sex } \\
\hline Female N (\%) & $20(60.6)$ & 17 (77.3) & $37(67.3)$ \\
\hline Male N (\%) & $13(39.4)$ & $5(22.7)$ & $18(32.7)$ \\
\hline \multicolumn{4}{|l|}{ Age (years) } \\
\hline Mean (SD) & $4 I .5(12.5)$ & $32.5(12.8)$ & $37.9(13.2)$ \\
\hline \multicolumn{4}{|l|}{ Asthma } \\
\hline$N(\%)$ & $14(42.4)$ & $6(27.3)$ & $20(36.4)$ \\
\hline \multicolumn{4}{|l|}{ Allergic rhinitis } \\
\hline$N(\%)$ & $25(75.8)$ & $12(54.5)$ & $37(67.3)$ \\
\hline \multicolumn{4}{|c|}{ Oral allergy syndrome } \\
\hline$N(\%)$ & $19(57.6)$ & $5(22.7)$ & $24(43.6)$ \\
\hline
\end{tabular}

Abbreviations: $\mathrm{N}$, number; SD, standard deviation. 
Table 2 Clinical results (source: pollen concentration, SCORAD, subjective parameters of pruritus and sleeplessness)

\begin{tabular}{|c|c|c|c|c|}
\hline Clinical details & Preseason & Peak & Postseason & $\begin{array}{l}P \text {-value* (sensitized } \\
\text { vs nonsensitized) }\end{array}$ \\
\hline Pollen concentration ( $\mathrm{m}^{3} / 24$ hours) & I & 185 & 1 & \\
\hline SCORAD for patients sensitized to birch pollen (mean) & 25.4 & 30.9 & 23.8 & 0.028 \\
\hline SCORAD for patients nonsensitized to birch pollen (mean) & 20.5 & 24.6 & 22.4 & \\
\hline Pruritus for patients sensitized to birch pollen (mean) & 3.2 & 3.8 & 3.3 & 0.843 \\
\hline \multicolumn{5}{|l|}{ Range: $0-10$} \\
\hline Pruritus for patients nonsensitized to birch pollen (mean) & 3.4 & 4.0 & 3.6 & \\
\hline \multicolumn{5}{|l|}{ Range: $0-10$} \\
\hline Sleeplessness in patients sensitized to birch pollen (mean) & 1.4 & 1.1 & I.I & 0.607 \\
\hline \multicolumn{5}{|l|}{ Range: $0-10$} \\
\hline Sleeplessness in patients nonsensitized to birch pollen (mean) & 1.6 & 1.2 & 1.6 & \\
\hline Range: $0-10$ & & & & \\
\hline
\end{tabular}

Note: *Represents 2-sample-t-test comparing the change from "peak" to "postseason" for sensitized vs nonsensitized patients.

Abbreviation: SCORAD, Severity Score of Atopic Dermatitis.

significantly worse on air-exposed skin than on covered skin areas $(P<0.0001)$, and improvement was seen after the end of the pollen season, significantly better for air-exposed skin $(P=0.0007)$. These results on subjective assessment were confirmed by the comparison of percentage of irritated skin. Increase at pollen peak was significantly higher on exposed areas than on unexposed skin $(P=0.039)$, as well as the decrease after pollen peak $(P=0.005)$. The most pronounced changes were seen on the face (Table 3 ).

The pruritus experienced by the patients subjectively increased by a delay of a number of days following peak pollen concentration (Figure 1). With increased pollen density, the pruritus became more severe $(P<0.1)$ and improved insignificantly after the end of the pollen flight $(P>0.1)$. For the subjective assessment of $\mathrm{AE}$ and pruritus, no difference was observed between the two groups (patients sensitized to birch pollen and patients nonsensitized to birch pollen; AE, $P=0.95$; pruritus, $P=0.843$ ).

The documentation of concomitant medication revealed no significant change throughout the whole period, confirming that the subjects complied in keeping their stable dose of topical treatment as instructed in the beginning.

Specific IgE against birch pollen does not automatically lead to higher SCORAD during or after the pollen season, as depicted in Figure 2.

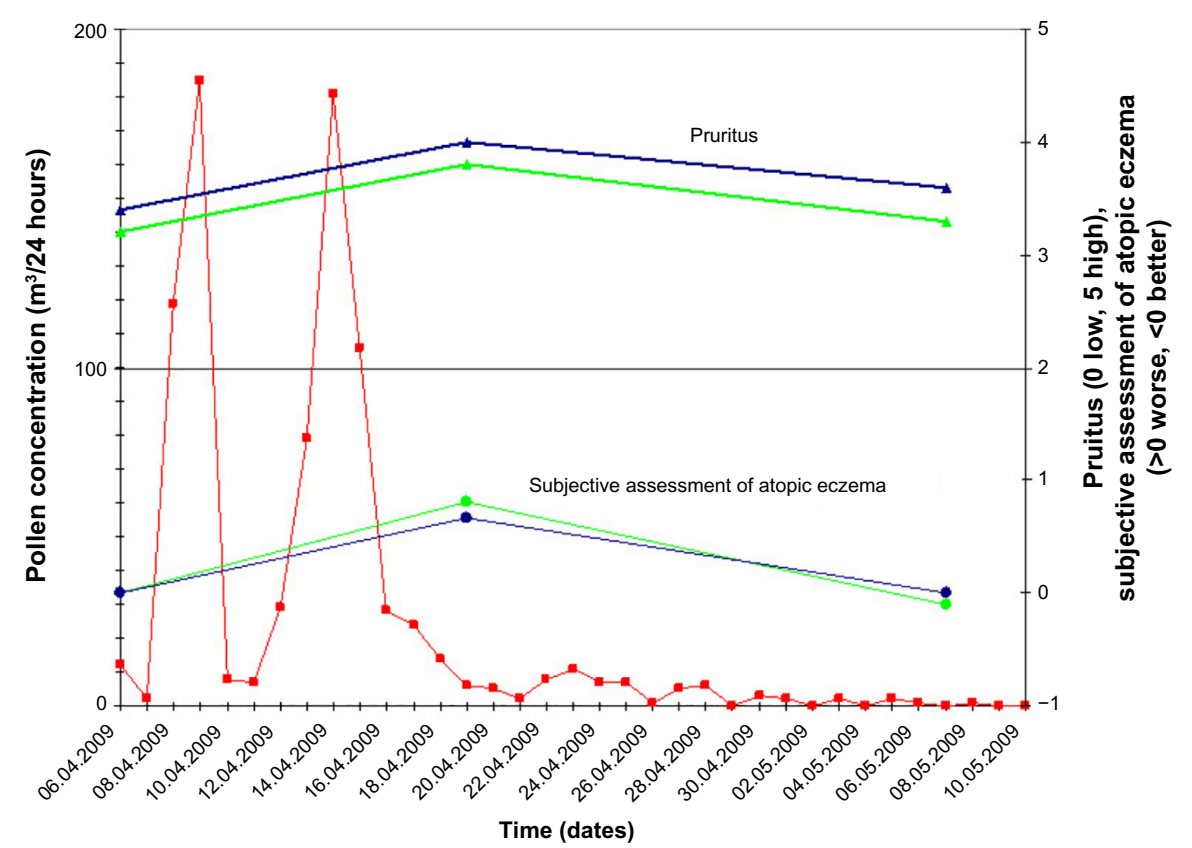

Figure I Pollen concentration (red squares), pruritus (triangle), and subjective assessment of atopic eczema (circles) for sensitized (green lines) and nonsensitized (blue lines) patients. 
Table 3 Change in the percentage of irritated skin (all exposed areas, face, nonexposed areas) over time

\begin{tabular}{lcccc}
\hline Time points & N & Mean & SD & Median \\
\hline Irritated skin (\% of all exposed areas) & & & & \\
$\quad$ Preseason & 43 & 25.3 & 26.3 & 15.0 \\
$\quad$ Peak & 55 & 32.5 & 29.3 & 20.0 \\
$\quad$ Postseason & 54 & 23.8 & 26.5 & 15.0 \\
Irritated skin (\% of the facial skin) & & & & \\
$\quad$ Preseason & 43 & 31.0 & 32.8 & 10.0 \\
$\quad$ Peak & 55 & 53.9 & 36.5 & 50.0 \\
$\quad$ Postseason & 54 & 33.6 & 34.4 & 22.5 \\
Irritated skin (\% of nonexposed areas) & & & & \\
$\quad$ Preseason & 43 & 14.5 & 24.5 & 5.0 \\
$\quad$ Peak & 55 & 15.8 & 26.4 & 5.0 \\
$\quad$ Postseason & 53 & 12.3 & 24.1 & 2.0 \\
\hline
\end{tabular}

Notes: $P$-value for Wilcoxon test - the change in the percentage of irritated skin from preseason to peak (exposed vs nonexposed areas) for preseason to peak $(0.038523)$ and peak to postseason $(0.005008)$ - were both statistically significant $(P<0.05)$.

Abbreviations: $\mathrm{N}$, number; SD, standard deviation.

\section{Experimental investigations of PA penetration into skin explants}

For the investigation, grass pollen proteins, as used for the prick test, were applied. Our group had previous experience with the fluorescence labeling of grass PA. Therefore, the experimental study was performed with grass PA, because no significant differences are expected in the penetration between birch and grass pollen proteins. Following the application of the PA to the barrierdisturbed skin and separation of the cells, in total, 211 MACS-separated CD1c+ epidermal cells were identified by laser scanning microscopy. In 40 identified cells, no fluorescence was observed (Figure 3A and B). A total of 171 of these cells showed a clear fluorescence, typical for fluorescein after having been excited at $488 \mathrm{~nm}$ (Figure 3C and D). The individual numbers of cells are given in Table 4.

After the PA had been applied to the healthy, undamaged skin, $231 \mathrm{CD} 1 \mathrm{c}+$ epidermal cells from 12 skin samples were investigated, 213 of which did not show any fluorescence. In 14 CD1c+ epidermal cells, a very weak fluorescence was observed. Only four cells could be detected, in which the fluorescence signal was almost as strong as in the skin sample previously damaged by CSSS. Figure 4 shows the relative amount of cells with and without fluorescence compared to the total number of MACS-separated epidermal cells. It exhibits the mean values \pm standard error for the untreated skin sample and the skin sample pretreated with CSSS. The respective skin samples show a high variance, with the differences in the mean values in Figure 4 being significant $(P<0.05)$.

\section{Discussion}

So far, there have been no investigations demonstrating a correlation between a relapse of the $\mathrm{AE}$ and a dermal contact to PA, notwithstanding the fact that this effect has been referred to in the literature several times..$^{2-5,14}$ In the present study, it was shown for the first time that there is a direct correlation between the skin exposure to PA and the manifestation of an $\mathrm{AE}$ and pruritus, respectively. Deterioration and recuperation of the skin was significantly different between exposed and cloth-covered (nonexposed) skin. Surprisingly, both sensitized and nonsensitized patients developed an exacerbation of AE during the birch pollen season. This may be explained by nonspecific influences of the pollen. Proteases damage the epidermal barrier, ${ }^{15,16}$ and pollen-associated lipid mediators lead to a Th2 response, which enhance the inflammation. ${ }^{17}$ To exclude confounding effects by other common inhalative allergens, these were measured using a pollen trap throughout the time of the study. Since only a small amount of other allergens of the same period were detectable (less than onetenth), they were considered of minor relevance. Also, effects of increased humidity and temperature may play a role in why both groups fail to return to the same low SCORAD as before the season.

The clinical data (SCORAD) acquired during the study were in full agreement with the subjective assessment of the patients concerning the severity of their disease.

In addition, our study presents explanations that are based on in vitro experiments on the uptake of PA by CD1c+ epidermal cells after topical applications of PA on barrierdisrupted skin. Obtaining the material to show this in atopic skin would be ethically unreasonable to perform in this study ( $4 \mathrm{~cm} \times 4 \mathrm{~cm}$ per subject).

Our results are in good agreement with the characteristic feature of the atopy to develop an increased inclination of becoming sensitive toward harmless environmental substances such as pollen. ${ }^{18}$ Due to the stronger exposure to pollen, the patients developed exacerbations, which can be explained by the results of the experimental investigations.

The precondition of $\mathrm{AE}$ is presumably the genetically determined disturbance of the epidermal barrier facilitating the penetration of environmental substances into the skin. This involves an immunologically induced inflammation, which is followed by sensitization. The filaggrin mutations have been associated with asthma (in association with AE) and food allergy, suggesting the mutation as a possible driver for the "atopic march". ${ }^{19-21}$

It is of importance that environmental antigens like house dust mite and pollen do not only evoke immediate allergic 


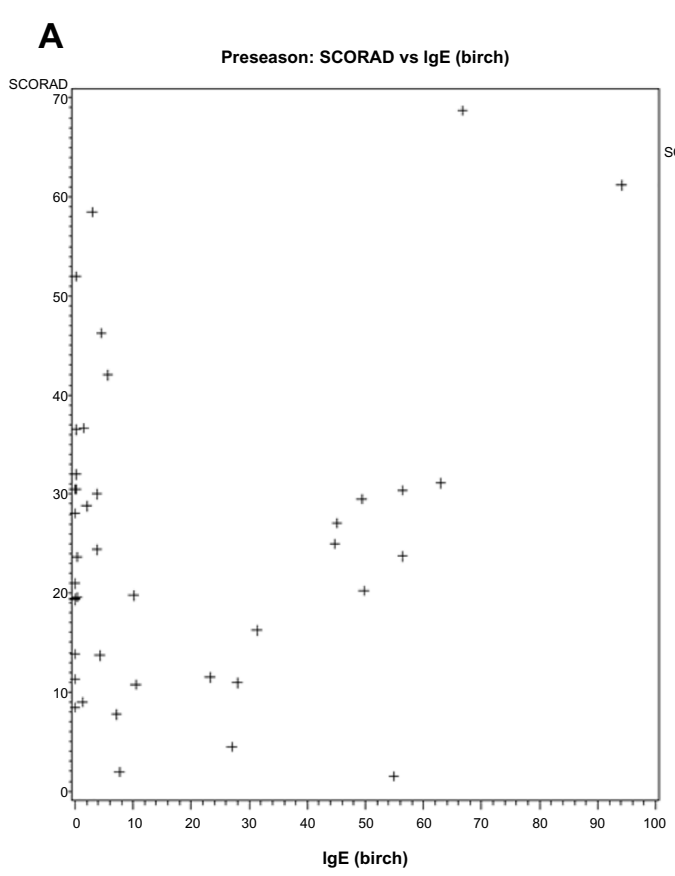

\section{B}
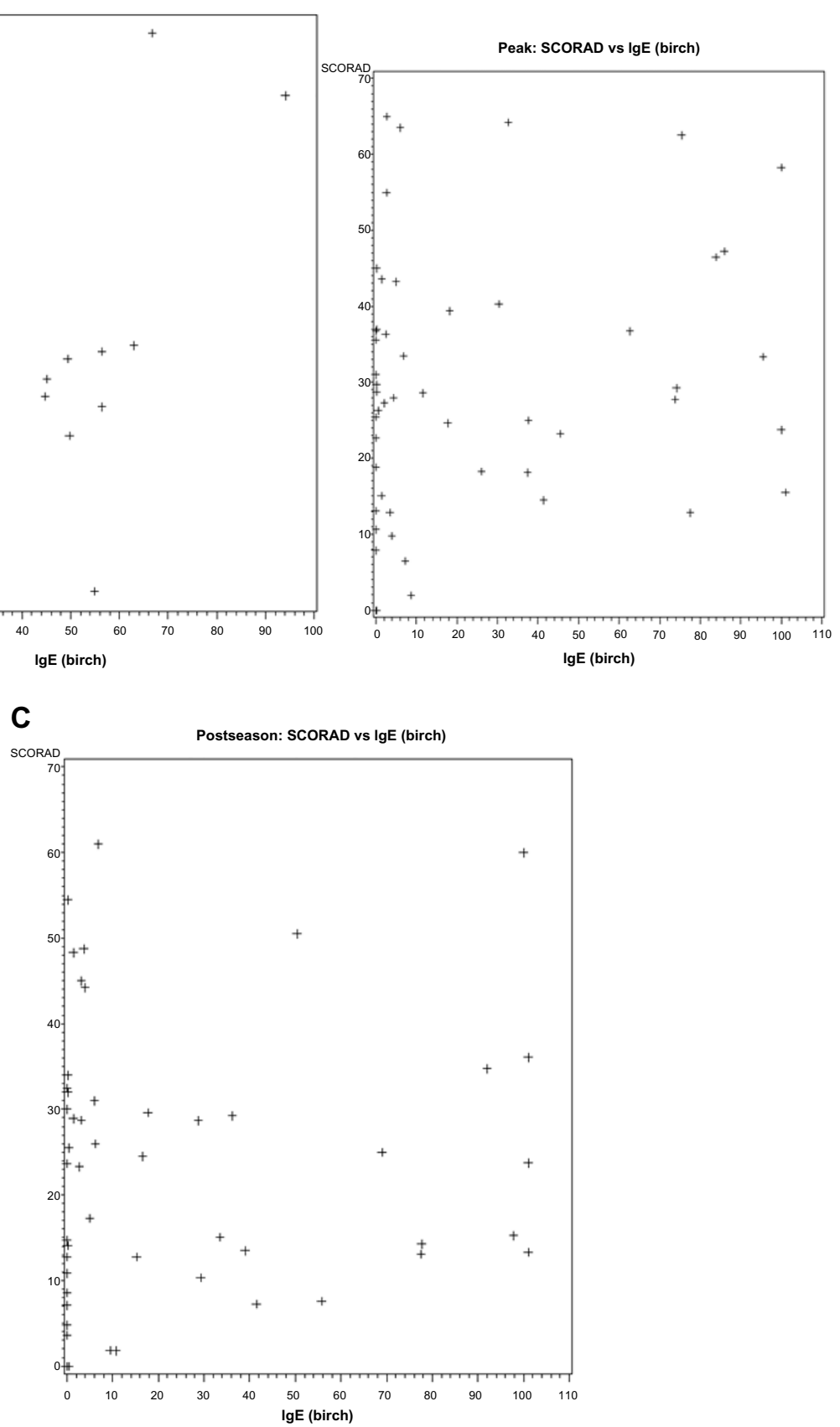

Figure 2 Specific IgE against birch pollen vs SCORAD.

Notes: (A) Before, (B) at peak of season, and (C) after the birch pollen season show that higher levels of lgE do not correlate with severity. Abbreviations: SCORAD, Severity Score of Atopic Dermatitis; IgE, immunoglobulin E.

reactions but they may also directly cause disturbances in the permeability barrier of the skin by acting as enzymes/ proteolytically active allergens. ${ }^{22-24} \mathrm{Also}$, the release of lipids from pollen, which exhibit chemical and functional similarities to leukotrienes and prostaglandins (pollen-associated lipid mediators), may contribute to exacerbations through the induction of a Th2 response. ${ }^{17}$ Interestingly, keratinocytes from atopic patients showed a significantly increased uptake of allergens as compared with healthy donors. ${ }^{25}$ Furthermore, nonallergic mast cell activation has also recently been found to be relevant in pollen-associated skin inflammation. ${ }^{26}$

A requirement for the influence of pollen on atopic skin is the penetration of the allergens into the skin. Therefore, we performed experimental analyses. MACS separation with anti-BDCA-1 (anti-CD1c) antibodies was performed twice, which resulted in over $90 \% \mathrm{CD} 1 \mathrm{c}+$ cells. ${ }^{13}$ Because 

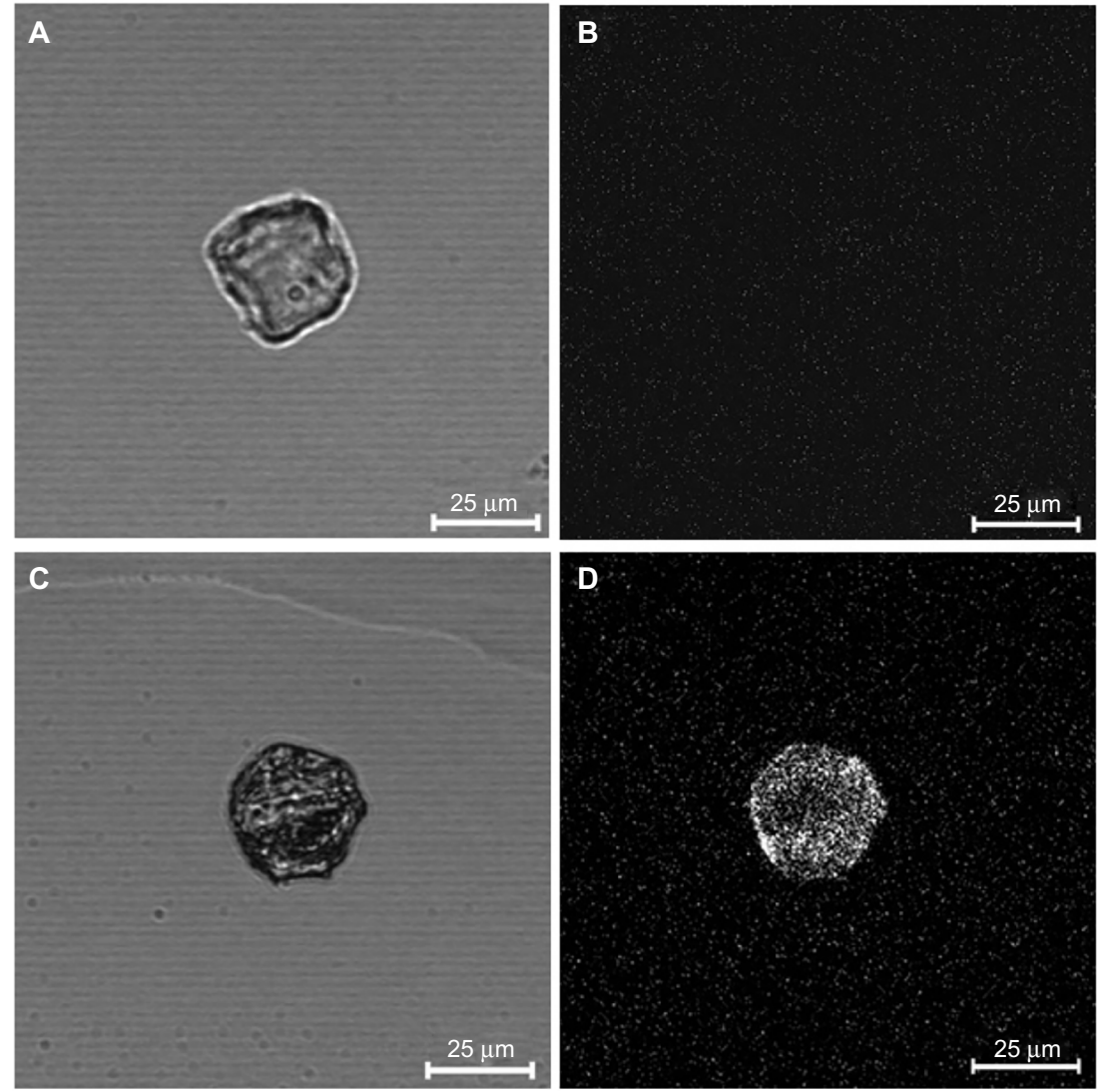

Figure 3 Laser scanning microscopy images of MACS-separated epidermal cells.

Notes: (A and B) Without and (C and $\mathbf{D})$ with fluorescence-labeled pollen allergens; $(\mathbf{A}$ and $\mathbf{C})$ transmittance and (B and $\mathbf{D})$ fluorescence mode. Abbreviation: MAC magnetic activated cell sorting.

the epidermis was separated from the dermis, most of the isolated CD1c+ cells are represented by Langerhans cells. Nevertheless, the detection of other dendritic cells or keratinocytes cannot be excluded.

Because our group had previous experience with the fluorescence labeling of grass PA, the experimental study was performed with grass PA. Significant differences were not expected in the penetration between birch and grass pollen proteins, and are esteemed to carry a similar burden of disease. ${ }^{27}$ For the investigation, grass pollen as used for the prick test was applied. Experiments using laser scanning microscopy showed that fluorescence-labeled PA can be detected in epidermal cell suspensions enriched with $\mathrm{CD} 1 \mathrm{c}+$ cells when the skin barrier was disturbed by CSSS. In intact healthy skin, such detection was not possible. This is in agreement with the investigations on nanoparticles carried out by Vogt et al, ${ }^{28}$ during which the uptake by Langerhans cells with $40 \mathrm{~nm}$ polystyrene particles could be detected only after CSSS. CSSS improves the follicular penetration of transcutaneously applied compounds by removing keratinized material, lipids, and other cell debris from the follicular openings and, occasionally, hair fibers, especially vellus hairs. ${ }^{29,30}$

In recent experiments, it was shown that particles obviously penetrate into the hair follicles at different depths dependent on the particle size. ${ }^{31}$ Likewise, PA have also been shown to penetrate into the skin via the transfollicular pathway. ${ }^{32}$ Thus, sensitization and a subsequent allergic reaction could be evoked in this way on other organs, where the

Table 4 Pollen uptake by CDI Ic+ epidermal cells from normal skin explants with and without barrier defects

\begin{tabular}{|c|c|c|c|c|c|c|c|}
\hline \multirow[t]{2}{*}{ Explant } & \multicolumn{4}{|c|}{$\begin{array}{l}\text { Number of cells without } \\
\text { pretreatment }\end{array}$} & \multicolumn{3}{|c|}{$\begin{array}{l}\text { CSSS pretreated } \\
\text { two times }\end{array}$} \\
\hline & Total & $\begin{array}{l}\text { No } \\
\text { FL }\end{array}$ & $\begin{array}{l}\text { Weak } \\
\text { FL }\end{array}$ & $\begin{array}{l}\text { Strong } \\
\text { FL }\end{array}$ & Total & $\begin{array}{l}\text { No } \\
\text { FL }\end{array}$ & $\begin{array}{l}\text { Strong } \\
\text { FL }\end{array}$ \\
\hline I & 31 & 28 & 3 & 0 & 99 & 25 & 74 \\
\hline 2 & 33 & 30 & 2 & I & 5 & 0 & 5 \\
\hline 3 & 61 & 56 & 3 & 2 & 25 & I & 24 \\
\hline 4 & 41 & 39 & 2 & 0 & 21 & 4 & 17 \\
\hline 5 & 35 & 33 & 2 & 0 & $4 I$ & 7 & 34 \\
\hline 6 & 30 & 27 & 2 & I & 20 & 3 & 17 \\
\hline
\end{tabular}

Abbreviations: CSSS, cyanoacrylate skin surface stripping; FL, fluorescence. 


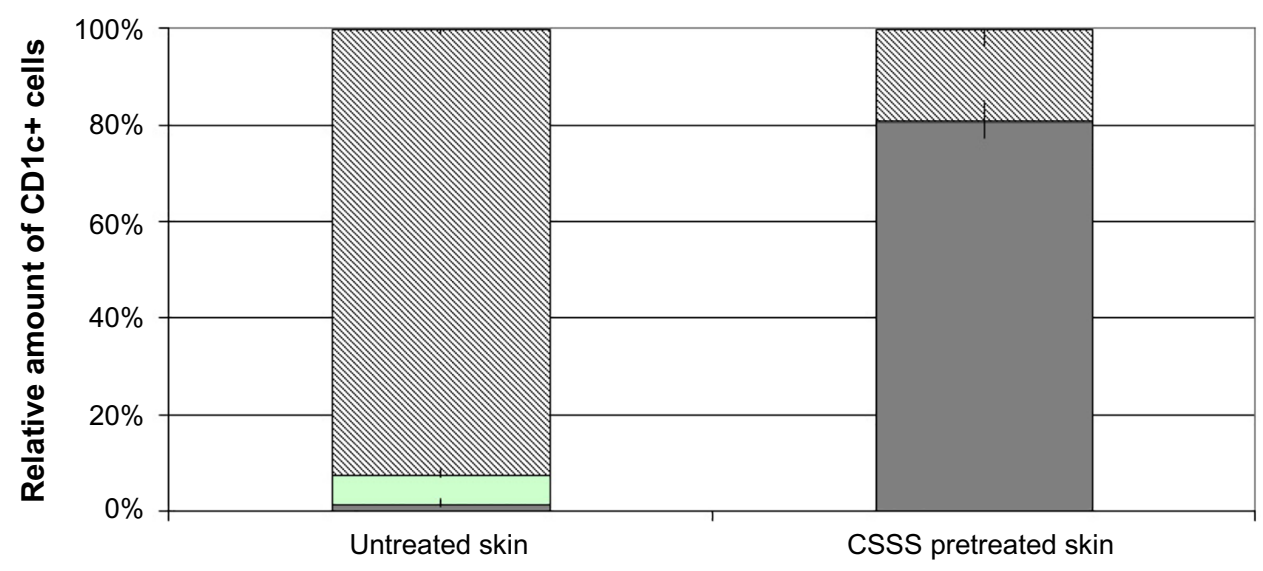

Pretreatment

Figure 4 Relative mean values \pm standard error for the number of MACS-separated cells with and without fluorescence after pollen allergen application to normal and barrier-disturbed skin.

Abbreviation: MACS, magnetic activated cell sorting.

atopic symptoms were also manifested. ${ }^{33-35}$ The hair follicles are an important target for allergens because they are surrounded by a dense network of dendritic cells. Also, it was demonstrated that the hair follicles represent a long-term reservoir for substances that come into contact with the skin. In contrast to the storage time of topically-applied substances in the stratum corneum, the storage time in the hair follicles can extend to 1 week. Hence, there is a considerable risk that allergens penetrating into the hair follicles may be effective there for an extended period of time, thus inducing skin irritations. A further incentive to this hypothesis is given by our data regarding the worsening of subjective symptoms, especially in uncovered body areas during the high-density pollen season, and a certain delay in the course of disease after changes in pollen burden.

Our results emphasize the importance of allergens for evoking an exacerbation of the AE. Based on these results, it is tempting to speculate that the treatment of skin with skin barrier-enhancing emollients might help to prevent an exacerbation of AE during the pollen season. ${ }^{36}$ In vitro experiments have already shown that certain emollients are able to prevent the follicular penetration of $\mathrm{PA},{ }^{32}$ and clinical studies are highly warranted in this respect. However, our study was limited by the low overall burden of pollen and by a small number of patients and controls, and it should be redone in a different year to minimize epiphenomenal influences.

\section{Acknowledgments}

The study was partly supported by Beiersdorf AG, Hamburg, Germany. KW (Hannover, Germany) was supported by an HILF
(Hochschulinterne Förderung) grant from Hannover Medical School. We would like to thank Sabine Schanzer for her assistance with isolating the dendritic cells, and Heike Richter for her support for performing the laser scanning microscopy images. The studies were supported by Beiersdorf AG.

\section{Disclosure}

The authors report no conflicts of interest in this work.

\section{References}

1. DaVeiga SP. Epidemiology of atopic dermatitis: a review. Allergy Asthma Proc. 2012;33(3):227-234.

2. Eichenfield LF, Ellis CN, Mancini AJ, Paller AS, Simpson EL. Atopic dermatitis: epidemiology and pathogenesis update. Semin Cutan Med Surg. 2012;31(3 Suppl):S3-S5.

3. Leung DY. New insights into atopic dermatitis: role of skin barrier and immune dysregulation. Allergol Int. 2013;62(2):151-161.

4. Chamlin SL, Kaulback K, Mancini AJ. What is "high risk?" a systematic review of atopy risk and implications for primary prevention. Pediatr Dermatol. 2009 May-Jun;26(3):247-256.

5. Bae JM, Choi YY, Park CO, Chung KY, Lee KH. Efficacy of allergenspecific immunotherapy for atopic dermatitis: a systematic review and meta-analysis of randomized controlled trials. J Allergy Clin Immunol. 2013;132(1):110-117.

6. Hanifin JM, Rajka G. Diagnostic features of atopic dermatitis. Acta Derm Venereol. 1980;92(Suppl):44-47.

7. Sher LG, Chang J, Patel IB, Balkrishnan R, Fleischer AB Jr. Relieving the pruritis of atopic dermatitis: a meta-analysis. Acta Derm Venereol. 2012;92(5):455-461.

8. Finlay AY, Khan GK. Dermatology Life Quality Index (DLQI) - a simple practical measure for routine clinical use. Clin Exp Dermatol. 1994;19(3):210-216.

9. Severity scoring of atopic dermatitis: the SCORAD index. Consensus Report of the European Task Force on Atopic Dermatitis. Dermatology. 1993;186(1):23-31.

10. Hirst JM. An automatic volumetric spore trap. Ann Appl Biol. 1952; 39(2):257-265. 
11. Jacobi U, Engel K, Patzelt A, Worm M, Sterry W, Lademann J. Penetration of pollen proteins into the skin. Skin Pharmacol Physiol. 2007;20(6):297-304.

12. Toll R, Jacobi U, Richter H, Lademann J, Schaefer H, Blume-Peytavi U. Penetration profile of microspheres in follicular targeting of terminal hair follicles. J Invest Dermatol. 2004;123(1):168-176.

13. Peiser M, Grützkau A, Wanner R, Kolde G. CD1a and CD1c cell sorting yields a homogeneous population of immature human Langerhans cells. J Immunol Methods. 2003;279(1-2):41-53.

14. Krämer U, Weidinger S, Darsow U, Möhrenschlager M, Ring J, Behrendt H. Seasonality in symptom severity influenced by temperature or grass pollen: results of a panel study in children with eczema. J Invest Dermatol. 2005;124(3):514-523.

15. Cork MJ, Robinson DA, Vasilopoulos Y, et al. New perspectives on epidermal barrier dysfunction in atopic dermatitis: gene-environment interactions. J Allergy Clin Immunol. 2006;118(1):3-21; quiz 22-23.

16. Meyer-Hoffert U. Reddish, scaly, and itchy: how proteases and their inhibitors contribute to inflammatory skin diseases. Arch Immunol Ther Exp (Warsz). 57(5):345-354.

17. Gilles S, Mariani V, Bryce M, et al. Pollen allergens do not come alone: pollen associated lipid mediators (PALMS) shift the human immune systems towards a T(H)2-dominated response. Allergy Asthma Clin Immunol. 2009;5(1):3.

18. Boralevi F, Hubiche T, Léauté-Labrèze C, et al. Epicutaneous aeroallergen sensitization in atopic dermatitis infants - determining the role of epidermal barrier impairment. Allergy. 2008;63(2):205-210.

19. Jung T, Stingl G. Atopic dermatitis: therapeutic concepts evolving from new pathophysiologic insights. J Allergy Clin Immunol. 2008;122(6):1074-1081.

20. Marenholz I, Kerscher T, Bauerfeind A, et al. An interaction between filaggrin mutations and early food sensitization improves the prediction of childhood asthma. J Allergy Clin Immunol. 2009;123(4): 911-916.

21. De Benedetto A, Kubo A, Beck LA. Skin barrier disruption: a requirement for allergen sensitization? J Invest Dermatol. 2012;132(3 Pt 2):949-963.

22. Roelandt T, Heughebaert C, Hachem JP. Proteolytically active allergens cause barrier breakdown. J Invest Dermatol. 2008;128(8): $1878-1880$
23. Takai T, Ikeda S. Barrier dysfunction caused by environmental proteases in the pathogenesis of allergic diseases. Allergol Int. 2011;60(1):25-35.

24. Jeong SK, Kim HJ, Youm JK, et al. Mite and cockroach allergens activate protease-activated receptor 2 and delay epidermal permeability barrier recovery. J Invest Dermatol. 2008;128(8):1930-1939.

25. Blume C, Foerster S, Gilles S, et al. Human epithelial cells of the respiratory tract and the skin differentially internalize grass pollen allergens. J Invest Dermatol. 2009;129(8):1935-1944.

26. Metz M, Gilles S, Geldmacher A, Behrendt H, Traidl-Hoffmann C, Maurer M. Evidence for non-allergic mast cell activation in pollenassociated inflammation. J Invest Dermatol. 2011;131(4):987-990.

27. Darsow U, Laifaoui J, Kerschenlohr K, et al. The prevalence of positive reactions in the atopy patch test with aeroallergens and food allergens in subjects with atopic eczema: a European multicenter study. Allergy. 2004;59(12):1318-1325.

28. Vogt A, Combadiere B, Hadam S, et al. $40 \mathrm{~nm}$, but not 750 or 1,500 nm, nanoparticles enter epidermal CD1 a+ cells after transcutaneous application on human skin. J Invest Dermatol. 2006;126(6):1316-1322.

29. Mills OH Jr, Kligman AM. The follicular biopsy. Dermatologica. 1983;167(2):57-63.

30. Schaefer H, Lademann J. The role of follicular penetration. A differential view. Skin Pharmacol Appl Skin Physiol. 2001;14 Suppl 1:23-27.

31. Patzelt A, Richter H, Knorr F, et al. Selective follicular targeting by modification of the particle sizes. J Control Release. 2011;150(1):45-48.

32. Meinke MC, Patzelt A, Richter H, et al. Prevention of follicular penetration: barrier-enhancing formulations against the penetration of pollen allergens into hair follicles. Skin Pharmacol Physiol. 2011;24(3): 144-150.

33. Berard F, Marty JP, Nicolas JF. Allergen penetration through the skin. Eur J Dermatol. 2003;13(4):324-330.

34. Incorvaia C, Frati F, Verna N, D'Alò S, Motolese A, Pucci S. Allergy and the skin. Clin Exp Immunol. 2008;153 Suppl 1:27-29.

35. Galli S, Tsai M, Piliponsky AM. The development of allergic inflammation. Nature. 2008;454(7203):445-454.

36. Billmann-Eberwein C, Rippke F, Ruzicka T, Krutmann J. Modulation of atopy patch test reactions by topical treatment of human skin with a fatty acid-rich emollient. Skin Pharmacol Appl Skin Physiol. 2002;15(2): $100-104$.
Clinical, Cosmetic and Investigational Dermatology

\section{Publish your work in this journal}

Clinical, Cosmetic and Investigational Dermatology is an international, peer-reviewed, open access, online journal that focuses on the latest clinical and experimental research in all aspects of skin disease and cosmetic interventions. All areas of dermatology will be covered; contributions will be welcomed from all clinicians and

\section{Dovepress}

basic science researchers globally. This journal is indexed on CAS The manuscript management system is completely online and includes a very quick and fair peer-review system, which is all easy to use. Visit http://www.dovepress.com/testimonials.php to read real quotes from published authors. 